\title{
Employee Motivation in Non-Profit: Evidence from a Community Based Voluntary Organization
}

\author{
Md. Mohiuddin ${ }^{1} \&$ Ms. Gurjit Dulay ${ }^{2}$ \\ ${ }^{1}$ Department of Finance, University of Chittagong, Bangladesh \\ ${ }^{2}$ Aston Business School, Aston University, UK \\ Corresponding: Md. Mohiuddin, Department of Finance, University of Chittagong, Bangladesh. Tel: \\ 880-193-052-1769. E-mail: mohiuddin2007@aol.com
}

Received: August 28, 2015

doi:10.5539/ijbm.v10n11p74
Accepted: September 21, $2015 \quad$ Online Published: October 28, 2015

URL: http://dx.doi.org/10.5539/ijbm.v10n11p74

\begin{abstract}
This paper explores employee motivation in one of the UK based voluntary organizations. It used a mixture of primary and secondary data. Primary data were collected in the form of questionnaires. By using Frederick Herzberg's two factor theory we found that, in the absence of sufficient financial rewards, non-financial rewards such as: extra days off for employees; implementation of employee of the month; and simple verbal recognition in an attempt to recognise employee's efforts were key motivating factors for the employees. Recommendations to management were made in terms of offering flexible hours and quality supervision in order to motivate unpaid volunteers.
\end{abstract}

Keywords: employee motivation, Herzberg, voluntary organization, content theory

\section{Introduction}

\subsection{Research Background}

The voluntary (Note 1) sector in the UK has recently seen a decline in government funding. This has caused tension within organizations as funding is declining therefore reducing the services they offer. This may cause a lack of organization in terms of people management and employee motivation. This had specifically come to the attention of one of the authors during the employment at ABC. (Note 2) Motivation of employees, recognition and reward systems are very much none existent at $\mathrm{ABC}$ which has proven to cause a lack of team cohesion and personal motivation amongst employees. This is something that needs to be put in to place at $\mathrm{ABC}$, to achieve a happier working environment and highly motivated staff which could potentially have an effect on job performance and the wider community. Although there is no pay for volunteer employees, not enough was done in terms of other incentives provided by the organization e.g. job recognition. $\mathrm{ABC}$ is a fairly small organization and therefore does not have the capabilities of having its own human resources department, consequently resulting in the issues it now faces. This has created a fairly idle recognition and reward system and a lack of understanding of people management in the organization, which may have caused a lack of motivation amongst employees. The change in management structure at $\mathrm{ABC}$ and uncertainty of who is in control may have also played a negative role in terms of employee motivation and team dynamics as employees were uncertain as to where the organization was heading and who is in control at the top. With such problems occurring at the organization, motivation of employees and staff morale was put on the back burner or none existent from the very beginning. This is a major problem within small organizations, such as $\mathrm{ABC}$, as employee goals may be not be the same, which leads to a lack of control and direction. If managers do not reflect their goals on to their employees through meaningful and motivating techniques this will result in individuals pursuing individuals' goals for the organization as opposed to overall team goals which will alter the message portrayed to the community.

\subsection{Research Objectives}

The objectives of this research are as follows:

-To examine what motivates employees in $\mathrm{ABC}$; and

-To come up with appropriate recommendations for $\mathrm{ABC}$ in order to increase employee motivation. 


\subsection{Case Overview}

$\mathrm{ABC}$ is a voluntary organization which caters for the needs of the community of Birmingham, UK. It is a service based organization that provides educational support, welfare support, health and employment support to the wider community. Recently, in August 2013 they have opened their own private nursery under the ABC brand. It is run by a combination of paid and unpaid staff. The organization is based on funding from many different bodies, here are a selection of a few funding organizations; 'Big Lottery Fund', 'Sportivate' and 'British Heart Foundation'. Without funding from these different bodies the organization will not be able to fund their activities to the local community, losing sight on their mission as a voluntary organization. Therefore, as well as running and monitoring projects employees focus on writing successful bids in a mission to try and fund more activities for the local community and to keep the organization running.

\section{Theoretical Literature Review}

\subsection{Definition of Motivation}

Guey et al. (2010) says motivation refers to the reasoning as to why people behave in such ways. Adimbola $(1977$, p. 124) found that "we are motivated when we freely pursue goals with energy and enthusiasm". Steers et al. (2004) conclude that motivation stems from the Latin word, Movever, which explains motivation is a means of expressing movement. These pieces of literature continue to explain that motivation has several meanings and it is very hard to measure and cannot be physically seen which needs to be kept in mind throughout this research.

\subsection{Motivation in Workplace}

Motivated employees in the workplace will lead to higher performance and ultimately higher business success therefore managers in organizations are continuously trying to find ways in which they can increase the intensity, reliability, quality and efficiency of employee performance (Kressler, 2003). In reality, every organization and every person is different therefore it is relatively difficult to pinpoint an exact method or technique that will motivate any individual in any workplace. Organizations may differ in terms of sector, location or characteristics and accordingly employ contrasting empowerment strategies to relate to their organization. In order to create a motivated workforce with effective team dynamics it is very important for managers to understand the workforce and the challenges that arise from motivating employees (French et al., 2011). It is argued that this is one of the largest complex challenges managers have to endure (Linder, 1998).

It is essential organizations do not fail to miss contextual factors and their effect on motivating the workforce in order to keep valuable employees. An individual's willingness to perform is related to the needs, wants and values of that individual and their link to the incentives that are linked to the organizations reward system (French et al., 2011). In terms of motivation at ABC this statement shows individuals willingness to perform would be fairly low due to lack of reward systems the business employs, however this is also dependable on individual values.

\subsubsection{Motivation in Voluntary Organizations}

Not much attention was paid in terms researching employee motivation in voluntary organization. This may be due to the size of the business and lack of resources (Lynas \& Dorrian, 1987). Various authors have suggested that goals and objectives for voluntary organizations are often best obtained by the use of intrinsically motivated employees as well as employees who sympathize with goals and objectives of the organization. This is something which we wish to identify in terms of employees at $\mathrm{ABC}$. There are many ways managers can use in order to encourage employee compliance with goals and objectives of the organization, this can be in terms of monitoring schemes and also incentives (Leete, 2000). Research has shown employees in voluntary organizations are more concerned meeting the needs of the public as opposed to extrinsic rewards displaying a very large commitment to the goals and objectives in which they work (Schepers et al., 2005). Whether this is the case in all Voluntary organizations is highly debatable and we will be looking at whether this is the case at $\mathrm{ABC}$.

\subsection{Theoretical Approaches}

In order to obtain an understanding of what motivates employees in the workforce, a number of motivational theories may be used. Theories on motivation are split into two groups, content and process. Content theories offer to explain the needs of an individual that are needed to motivate their behaviour and that make them feel a certain sense of satisfaction (Robertson et al., 1992). Four of the best known content theories were proposed by Maslow, Alderfer, McClelland and Herzberg (French et al., 2011). Process theories of motivation explore the thought processes that go through an individual's mind and how these effect motivation (Robertson et al., 1992). 
After much deliberation into what theory fits best for this research, Herzberg's two factor theory was chosen. The choice of this theory was based on the empirical research that has gone into it. Herzberg's theory has been used in many studies such as a study on employee motivation in Korea (Usugami \& Park, 2006), Brazilian hotel workers (Sledge et al., 2008) and also within management carried out by Berl and Williamson (1987). The diversity of the studies that have used Herzberg's model shows it can be used in many circumstances and does not solely target a specific group of people, area or sector. This theory can be used in the voluntary sector even though it was not developed in this context. It is also universal and therefore can be applied cross-culturally; however there is still research to be conducted in this area (Sledge et al., 2008). The large amount of empirical research was the primary reason for choosing Herzberg's two factor theory.

\subsubsection{Herzberg's Two Factor Theory}

Frederick Herzberg developed a new way of thinking when it came to motivation; he believed job enrichment was the core to motivating employees in the workplace (Lazenby, 2008). Herzberg's research was carried out to determine which factors promoted positivity and warmth and which factors promoted negativity within the workplace. The research was drawn from statements from 200 respondents whom were all from a technology and business background (Kressler, 2003). The 200 respondents were asked to describe times in their jobs where they felt extremely good or bad and describe their feelings drawing from these particular circumstances.

After a thorough analysis of these 200 statements it was revealed that there are two groups of factors relating to work motivation that could either cause satisfaction or dissatisfaction at work (Kressler, 2003). One group of factors are most named hygiene factors that interact between no job dissatisfaction and job dissatisfaction, these factors are related to job context and work based settings. In their presence they are unable to support job satisfaction meaning they do not act as a motivator, but merely dismiss job dissatisfaction. In their absence job dissatisfaction occurs. The second group of factors act as motivators and cover the aspects of the job that can lead an individual from being not satisfied and motivated to satisfied and motivated, these factors are related to job content that is, what employees do in their work. Herzberg believes when these factors are absent employees will not be satisfied and performance will not increase (Herzberg, 1966). Examples of hygiene factors and motivators are highlighted in the table below.

Table 1. Hygiene and motivation factors

\begin{tabular}{ll}
\hline Hygiene factors & Motivation factors \\
\hline Company policy and administration & Advancement \\
Work Conditions & Growth \\
Personal Life & Achievement \\
Status & Recognition \\
Salary & Work Itself \\
Relationships with peers and supervisor & Level of responsibility \\
Job Security & \\
Quality of Supervision & \\
\hline
\end{tabular}

Source: Source: Herzberg, 1966.

Although pay is genuinely perceived as being a positive reinforcement in the workplace and a factor in motivating employees, Herzberg's findings and analysis draws away from this hypothesis. Herzberg's two-factor model directly challenged the norms of society as researchers in the past believe money was the heart of motivating employees (Basset-Jones \& Lloyd, 2005). He found that pay does not act as a motivator but however causes job dissatisfaction. It is undeniable that poor pay has a dissatisfying effect on work ethic and overall view of work. This dissatisfaction eventually grows and a person's attitude towards; work, the job itself and the organization they work in, will eventually change over time. This will cause a person to have a negative mind set towards work (Kressler, 2003).

A point to take into consideration whilst analysing Herzberg's model is that all factors mentioned above were weighted on both sides; that of hygiene and motivator. The deciding factor for when it came to categorizing each element was how heavily weighted it was on each side, the higher the weight would mean the element would be 
assigned to that category.

Basset-Jones and Lloyd (2005) looked into Herzberg's model and produced an article called "Does Herzberg's motivation theory have staying power?" From this article it was found one of the most influential criticisms of Herzberg's model was put forward by Vroom a fellow researcher into motivation. Vroom questioned the methodology of Herzberg's theory as in a recall study respondents would answer questions to benefit themselves. Other critiques have also criticised the methodology of the research and have been astonished that money does not act as a motivator (Basset-Jones \& Lloyd, 2005). Herzberg has also received criticism from Sledge et al. (2008), as they have stated the model is very simplistic in terms of the explanation of job satisfaction as well as the lack of consideration to different cultures.

Others have criticised the contrast between motivator and hygiene factors and find it difficult to find the difference between the two. They also question the fact individual differences and needs of an individual are not taken into account and that pay can also act as motivator (Lundberg et al., 2009).

\section{Research Method}

In order to achieve the research objectives it is important to hear from the employees themselves and their feelings towards motivation. This is achieved in the form of a questionnaire which generates quantitative results. The questionnaire will give an insight to each employee's motivation and find out what essentially motivates them in the workplace. The questionnaire was given to all members of staff at $\mathrm{ABC}$ and also previous staff members who have worked at $\mathrm{ABC}$. The idea to have previous members of staff to fill out the questionnaire was chosen to gather a greater understanding of employee motivation at $\mathrm{ABC}$.

Bell (1991) advises researchers to gain consent with respondents before carrying out any research and to inform them about the reasoning behind the research and the possible benefits of it. Therefore, participants were asked for their consent. Participants were made aware that they are able to disengage with the research at any time as well as being enlightened that the questionnaire would remain anonymous (Clough \& Nutbrown, 2002). The reliability of questionnaires may be questioned as Denscombe (2003) suggests many respondents may give untruthful responses in an act to be socially desirable.

The questionnaire consists of 22 questions/statements drawing from Herzberg's theory. It will be based on a rating scale reflecting a quantitative approach. This approach can benefit the research as it will allow the researcher to analyse results relatively quicker (Denscombe, 2003), as well as benefiting respondents as they are able to choose from a list of options and save time when completing the questionnaire (Kirklees, 2008). However, choosing to apply a structured questionnaire may question validity of the research as such questionnaires may restrict responses from respondents where respondents feel the need to expand on the matter in question (Cramer \& Bryman, 1997). This can cause frustration amongst some participants and therefore they may feel they do not want to participate in the research due to lack of opportunity to express themselves (Densombe, 2003). The questionnaire was given to all staff who currently work at $\mathrm{ABC}$ and past staff members, equalling to a total of 25 . The questionnaire yielded a response of 20 respondents, 10 unpaid staff members and 10 paid staff members. Taking this into consideration, it was decided to allow participants to provide 'further comments and recommendations' at the end of the questionnaire. Using both types of research can increase the usefulness of the data (Best \& Khan, 1989). This allows respondents to provide their own opinions and therefore the researcher can achieve some aspect of 'depth' rather than breadth' (Blaxter, Hughes, \& Tight, 1996). However as mentioned above some respondents may feel it is time-consuming and therefore ignore the option to provide further comments. Data were analyzed by using simple statistical methods such as average, percentages etc.

\section{Findings and Analysis}

\subsection{Motivators}

\subsubsection{Career Advancement}

Stemming from employee responses it can be seen that there is a mixture of thoughts in relation to career advancement opportunities at ABC. Majority of respondents feel there are little career advancement opportunities with 5 out of those feeling a strong belief towards this which is highlighted in the bar chart. We can also see that career advancement is very important to majority of respondents and is a factor that contributes to each respondent's motivation which complies with Herzberg's two factor theory. However, there are a small selection of respondents that feel career advancement does not act as a motivator for themselves this may be due to that fact their primary aim is to help and support the local community as $\mathrm{ABC}$ is voluntary organization. Career advancement is somewhat not available at $\mathrm{ABC}$ due to the size of the organization and therefore employees may feel that there is, in reality little room for growth in terms of career and individual growth. ABC 
has a management team of three people who are very close and it is very difficult to integrate and there are no other platforms to grow, such as 'department leader' as departments do not exist in an organization of this size. Therefore resulting in employees at $\mathrm{ABC}$ to feel in this particular way, and questions why employees will stay if they feel there is little room to progress within the organization especially if this is a factor of individual motivation.

\subsubsection{Achievement}

Achievement is a factor that motivates all respondents which is highlighted above. A sense of achievement to be a motivator at $\mathrm{ABC}$ was expected to be high as it is a non-profit making organization and therefore employees want to feel they are making a difference to those who are less deprived then themselves. This showing achievement is connected to results. This is achieved by writing successful funding bids in order to provide more activities/courses for people from the local community. Many of the courses provided are free of charge for users. Achievement and results can be seen to be one of the most important aspects for an employee in the non-profit sector as their primary aim is to help and support others. Thus it seems obvious that such a factor will motivate. It is fair to assume if employees at $\mathrm{ABC}$ do not receive any results from their efforts that the employee's motivation will decrease. Results include getting members of the public back into work, providing the youth with activities to keep them off the streets etc. However, it was found that a proportion of respondents feel they do not feel a sense of achievement at $\mathrm{ABC}$. This may be due to the fact that those respondents do no to comply, or have not already, complied with the organizations goals and objectives and therefore the organizations results are not of great interest to them. This may be due to the lack of management portraying their goals on to employees through meaningful and motivating techniques, thus employees and management's ideas may differ. This expresses the need for management to portray goals and objectives onto employees, through meaningful and motivating techniques.

\subsubsection{Recognition}

Recognition is a factor that motivates all staff at $\mathrm{ABC}$ except for one, this complies with Herzberg's two factor theory. Only three respondents have stated they gain recognition for their work, with majority feeling they do not. Recognition is an important factor to majority at $\mathrm{ABC}$ and with many feeling they are not recognised for their work, this has created lower job productivity and less motivated staff. Ten respondents are employed on an unpaid basis contract meaning tangible items are idle therefore recognition is seen to be very important amongst these employees as well as those who are on a paid contract. Members of staff may look to managers and supervisors recognising their work, this may be in the form of verbal encouragement, incentives and also small gestures. These factors will show an employee how appreciated they are within the company and in turn produce a harder working and more motivated workforce at ABC. Staff will feel revitalised and may work harder in an attempt to provide more activity for the local community which is the overall purpose of the organization.

\subsubsection{Job Content}

It can be seen from the bar chart that job content is very important for every respondent in terms of motivation. All respondents feel job content acts as a motivator for them which complies with Herzberg's theory. Job content may be particularly important for employees at $\mathrm{ABC}$ as is it is a voluntary organization, therefore employees feel the need for their work to be important and relate to the needs of the local community in a chance to better their lives. The bar chart illustrates thirteen respondents out of twenty are not happy with their job content which questions the motives of these individuals. From the literature review it was found that non-profit organizations work best with intrinsic motivated employees and employees who comply with the organizations goals and objectives. Job content at $\mathrm{ABC}$ relates to the needs of the community and creating further opportunities for them i.e. the goals and objectives of the organization. This may mean employees do not configure with the goals and objectives of the organization which supports the evidence found.

\subsubsection{Level of Responsibility}

According to Herzberg's theory, level of responsibility is important when it comes to motivating employees. This is also the case at $\mathrm{ABC}$. It can be seen majority of respondents have concluded they are satisfied with the level of responsibility they have within their jobs or they are undecided. It is also seen as a motivator for all respondents. This is great for $\mathrm{ABC}$ as it shows employees feel motivated in terms of the responsibility they have at work. Due to the low number of staff employed at $\mathrm{ABC}$ at one time it can be seen each employee whilst working at $\mathrm{ABC}$ feels they have a sense of responsibility which is great for the organization as individual motivation is increased. 


\subsection{Hygiene Factors}

\subsubsection{Working Conditions}

Working conditions are not an issue at $\mathrm{ABC}$ which can be seen in the bar chart, it is also not seen as a factor of motivation which agrees with Herzberg's theory. This eliminates dissatisfaction in relation to working conditions amongst employees at ABC. Expressing working conditions, such as amount of work, office space, lighting etc. are pleasant for workers at $\mathrm{ABC}$, which is great for the organization. however, this is not a factor of motivation for staff.

\subsubsection{Salary}

Salary and earning a living is very important to the majority however whether or not it acts as a motivator or not is questioned. Questions on salary were split into three where one focuses on those who were in paid positions, one on those who are in an unpaid position and one relating to both.

All respondents felt that salary is a factor that motivates them which contradicts Herzberg's theory as he stated salary was only a hygiene factor. Meaning that salary cannot motivate an individual and in fact can only dismiss dissatisfaction however this not the case at ABC. To further contradict Herzberg, unpaid staff believe receiving a salary will dramatically increase motivation. This may somewhat seem obvious as Herzberg stated that salary is used as a factor to eliminate dissatisfaction in employees and therefore employees in an unpaid position will feel a sense of motive if they were known to start receiving a salary. If they started out in a paid position this may be different. However this still contradicts Herzberg's theory.

Majority of those in paid positions feel pleased with their salary however four out of the ten respondents who are in a paid position are not satisfied. This shows they feel they should be paid more for they work they do which will cause an employee to have a negative mind set, expressing management at $\mathrm{ABC}$ may need to rethink in terms of salary paid out to employees.

\subsubsection{Relationship}

Half of the respondents are dissatisfied with their relationships between peers and supervisors as well as twelve respondents feeling relationships with peers and supervisors is a personal factor of motivation. A lack of positivity towards relationships at $\mathrm{ABC}$, for some staff members, may be due to the lack of team dynamics, communication between staff members as well as all team members not working to a common goal. In relation to building a rapport between team members and staff it can be said nothing was practically done. Ice breakers and team building exercises which can help build team rapport are none existent at $\mathrm{ABC}$ which has consequently introduced negativity amongst some employees in regards to working relationships. This shows management need to look into ways to incorporate fun activities in the workplace to promote team work and positive peer relationships. However all staff members do not feel negativity towards their relationships at $\mathrm{ABC}$ demonstrating that some staff members are satisfied with this factor. Twelve out of twenty respondents feel that positive relationships contribute to their motivation. Herzberg believed this was a hygiene factor and therefore cannot contribute to an individual's motivation. This may be important to some members of $\mathrm{ABC}$ as the organization is fairly small in terms of the number of staff members therefore it is important to have fulfilling relationships with one another in an aid to increase employee motivation and performance.

\subsubsection{Job Security}

Job security at $\mathrm{ABC}$ is somewhat questionable due to the fact the organization is a voluntary organization and relies on the government and other national bodies to fund its activities. Majority of respondents feel they are not satisfied with their overall job security. As the organization relies on funding, if funding declines this will also have a negative effect on an employee's job security and state of mind causing employees at $\mathrm{ABC}$ to become dissatisfied with their role. This may be the primary reason employees at $\mathrm{ABC}$ think negatively about their overall job security. Majority have also stated they do not see job security as a motivator which agrees with Herzberg's theory, however those who see it is a motivator may feel this way due to the fact that positive job security is difficult to obtain at $\mathrm{ABC}$ and therefore they believe it will motivate them.

\subsubsection{Supervision}

The questionnaire has yielded mixed responses in terms of the quality of supervision at work. Seven respondents stated they are pleased with the supervision they receive whereas seven stated they are not and six being undecided. This expresses some employees feel the level and quality of supervision at work is good and are not dissatisfied by this factor at $\mathrm{ABC}$. However others feel it is not, this could be due to the fact managers and supervisors do not look over their work making employees feel their work isn't valued in the workplace, thus 
causing dissatisfaction. However no respondents feel that the quality of supervision is in fact a motivator which agrees with Herzberg's theory.

\subsection{Further Comments}

Further comments and recommendations question was only completed by eight respondents, reasons for this occurring are expressed in the 'research methods' section of this research. Five respondents expressed their feelings about recognition in the workplace. They had stated it is a factor they feel very strongly about and the workplace need to incorporate reward systems in their management styles in order to increase personal motivation. Three respondents went on to express that they feel unpaid staff members should work on a flexible basis, as some working hours staff members are 'idle' in offices, with not much work to do. These respondents were unpaid staff members.

\section{Discussion and Conclusion}

From analysis the questionnaires it was found that, majority of staff are not motivated at. In relation to Herzberg's theory, and his proposed motivators, employees at $\mathrm{ABC}$ comply with his theory showing motivation at $\mathrm{ABC}$ can be explained with the use of this theory, however there were also some contradictions. Career advancement, achievement, recognition, job content are all factors of motivation for employees at ABC. However a lot of these factors are not present within employees at $\mathrm{ABC}$ which is the reasoning behind de motivated employees. In order for $\mathrm{ABC}$ to achieve a harder working and motivated workforce they need to try and meet if not all, but some factors of motivation. Recognition for hard work was one of the least factors that employees identified with. This showing $\mathrm{ABC}$ management team does not do enough in terms of recognizing employees work and skills. This is particular important for employees who do not receive any tangible rewards for their efforts. This shows ABCs management team need to look at ways in which they can use, to recognise and appreciate employee efforts. With recent funding being at a decline at $\mathrm{ABC}$, financial rewards are very hard to come by, however this does not assume non-financial rewards are forgotten. Management can offer employees extra days off, implement employee of the month wall chart and integrate higher flexibility as well as simple verbal recognition in attempt to recognise employee's efforts. Career advancement was also a factor many did not identify with; however majority said it was a factor of motivation. Whether employees came into the organization for the possibility of career growth is somewhat questionable due to the size of the organization therefore questioning if these questions were suitable for employees at ABC. Also, in contradiction to Herzberg's theory a small proportion of respondents were not motivated by career growth, which may be due to the nature of the organization, again questioning whether Herzberg's model fits in with employees at ABC. To contradict Herzberg's theory twelve out of twenty respondents felt relationships were in fact a factor of motivation as well as all respondents feeling salary was also a factor of motivation. This showing Herzberg's theory does not $100 \%$ correlate with employees at $\mathrm{ABC}$. A hygiene factor that majority of employees were not happy with was there sense of job security. This has occurred due to decline in funding in the last couple of years and is something managers need to try and tackle in order for employees to gain a sense of stability.

In terms of written recommendations proposed by employees, it was noted by a small number of employees to introduce flexible working hours for those on an unpaid contract. This may consequently improve unpaid staff members motivation. This is something managers at $\mathrm{ABC}$ may want to think about in the future.

Overall it can be said a large amount of employees are not happy at $\mathrm{ABC}$ or were happy whilst working there in the past. Aspects of Herzberg theory has proved to fit within employees at ABC. Results that were obtained were very much expected and it can be said more needs to be done in motivating employees at $\mathrm{ABC}$. These findings contribute to knowledge in terms of understanding which factors motivates employees in voluntary sector organizations.

However, the paper is not limitation free. It includes the simplicity of the questionnaire. The questionnaire could have included much more questions to gather a better idea within specific aspects of motivation as opposed to general questions which were solely based on Herzberg's theory. Also, as only a selected number of participants answered the open ended question, it may have been worthwhile to ask more of these style questions to generate personal and detailed opinions. Also, due to the small amount of employees at $\mathrm{ABC}$, it was chosen to ask past year staff members to complete the questionnaire, interviews with current staff members may have been more suitable.

An area that will be interesting to investigate in future at $\mathrm{ABC}$ in terms of motivation is the managerial view as opposed to the employees view. It will be interesting to find what management feel in terms of motivating employees. As some managers may feel that employees who opt to work for a voluntary organization may not need to be motivated in terms of the aspects mentioned in this research by Herzberg. To investigate this it may be 
useful to use a dialogue technique whereby management and employees discuss each other's expectations.

\section{References}

Abimbola, A. (1997). Motivating staff in Nigerian university libraries. Library Management, 18(3), 124-128. http://dx.doi.org/10.1108/01435129710166437

Basset-Jones, N., \& Lloyd, G. C. (2005). Does Herzberg's motivation theory have staying power? The Journal of Management Development, 24(10), 929-943. http://dx.doi.org/10.1108/02621710510627064

Bell, J. (1991). Doing your research project (2nd ed.). Milton Keynes: Open University Press.

Berl, R. K., \& Williamson, H. C. (1987). A review of the content theories of motivation as they apply to sales and sales management. American Business Review.

Best, J., \& Khan, J. (1989). Research in Education. Englewood Cliffs (NJ), Prentice Hall.

Blaxter, L., Hughes, C., \& Tight, M. (1996). How to Research. Buckingham, Open University Press.

Clough, P., \& Nutbrown, C. (2002). A student's Guide to Methodology. London: SAGE.

Cramer, D., \& Bryman, A. (1997). Quantitative Data Analysis. England: London: Routledge.

Denscombe, M. (2003). The Good Research Guide (2nd ed.). England: Open University Press.

French, R., Rayner, C., Rees, G., Rumbles, S., Schermerhorn, J., Hunt, J., \& Osborn, R. (2011). Organizational Behaviour (2nd ed.). West Sussex: John Wiley \& Sons.

Guay, F., Chanal, J., Ratelle, C. F., Marsh, H. W., Larose, S., \& Boivin, M. (2010). Intrinsic, identified, and controlled types of motivation for school subjects in young elementary school children. British Journal of Educational Psychology, 80(4), 711-735. http://dx.doi.org/10.1348/000709910X499084

Herzberg, F. (1966). Work and the nature of man. New York: The Word Publishing Company.

Kirklees. (2008) Questionnaires. Retrieved

from http://www.kirklees.gov.uk/community/yoursay/Questionnaires.pdf

Kressler, H. (2003). Motivate and Reward. Hampshire: Palgrave Macmilan. http://dx.doi.org/10.1057/9781403937711

Lazenby, S. (2008). How to motivate employees: What research is telling us? Public management, 90(8), 22-25.

Leete, L. (2000). Wage equity and employee motivation in non-profit and for-profit organizations. Journal of Economic Behaviour \& Organization, 43, 423-446. http://dx.doi.org/10.1016/S0167-2681(00)00129-3

Linder, J. R. (1998). Understanding employee motivation. Research in Brief, 36(3).

Lundberg, C., Gudmundson, A., \& Andersen, T. (2009). Herzberg's two-factor theory of work motivation tested empirically on seasonal workers in hospitality and tourism. Tourism management, 30(6), 890-899. http://dx.doi.org/10.1016/j.tourman.2008.12.003

Lynas, M. G., \& Dorrian, A. P. (1987). Managing the smaller firm (1st ed.). Johannesburg: Southern Book.

Robertson, T. I., Smith, M., \& Cooper, D. (1992). Motivation: Strategies, Theory and Practice (2nd ed.). London: Institute of Personnel Management.

Schepers, C., Gieter, S., Pepermans, R., Bois, C., Caers, R., \& Jegers, M. (2005). How are Employees of the non-profit Sector Motivated? A Research Need. Non-Profit Management \& Leadership, 16(2), 191-208. http://dx.doi.org/10.1002/nml.100

Sledge, S., Miles, A. K., \& Coppage, S. (2009). What role does culture play? A look at motivation and job satisfaction among hotel workers in Brazil. The International Journal of Human Resource Management, 19(9), 1667-1682. http://dx.doi.org/10.1080/09585190802295157

Steers, R., Mowday, R., \& Shapiro, D. (2004). The Future of Work Motivation Theory. Academy of Management Review, 29(3), 379-387. http://dx.doi.org/10.5465/AMR.2004.13670978

Usugami, J., \& Park, K. (2006). Similarities and differences in employee motivation viewed by Korean and Japanese executives: Empirical study on employee motivation management of Japanese-affiliated companies in Korea. The International Journal of Human Resource management, 17(2), 280-294. http://dx.doi.org/10.1080/09585190500404697 


\section{Notes}

Note 1. Voluntary organization and the non-profit organization were used interchangeably.

Note 2 . The real name of the organization was not used in order to provide for confidentiality purpose.

\section{Copyrights}

Copyright for this article is retained by the author(s), with first publication rights granted to the journal.

This is an open-access article distributed under the terms and conditions of the Creative Commons Attribution license (http://creativecommons.org/licenses/by/3.0/). 